\title{
Superior oblique tendon lengthening for acquired superior oblique overactions
}

\author{
Ruth M Manners, Elizabeth O’Flynn, Robert J Morris
}

\begin{abstract}
Two patients who presented with compensatory head postures and diplopia are described. They both had marked unilateral superior oblique overaction, in one patient due to a large, incomitant skew deviation. Each underwent a superior oblique tendon lengthening procedure using a segment of silicone $\mathbf{2 4 0}$ retinal band as an expander, in combination with a contralateral superior rectus recession. Both achieved an excellent result with an improvement of the compensatory head posture and an increase in the field of binocular single vision. This surgical procedure is proposed as an option in the management of superior oblique overaction, including certain cases of skew deviation.
\end{abstract}

(BrF Ophthalmol 1994; 78: 280-284)

Surgical options for the management of superior oblique overaction or Brown's syndrome ${ }^{1}$ are various. ${ }^{2}$ They include tenotomy or tenectomy of the superior oblique tendon ${ }^{3}$ or recession of the superior oblique muscle. ${ }^{4}$ However, these procedures are associated with complications. The commonest of these are failure to perform adequate tenotomy resulting in unpredictable results $^{5}$ and postoperative superior oblique

The Eye Hospital, Wilton Avenue, Southampton, Avenue, Southampton, R M Manners E O'Flynn

R J Morris

Correspondence to:

Mr R J Morris.

Accepted for publication 21 October 1993 underaction..$^{5-8}$ Other complications include postoperative adhesive syndrome owing to fibrosis around the superior oblique tendon creating a simulated Brown's syndrome, and inadvertent severing of the superior rectus. ${ }^{57}$

A technique for weakening the superior oblique muscle by lengthening its tendon has been described by Wright ${ }^{9}$ and used in the
Table 1 Patient 1: preoperative measurements of ocular deviation

\begin{tabular}{|c|c|c|}
\hline $\begin{array}{l}30 \text { RHT } \\
10 \text { RXT }\end{array}$ & $\begin{array}{l}20 \mathrm{RHT} \\
10 \mathrm{RXT}\end{array}$ & $\begin{array}{l}8 \text { RHT } \\
4 \text { RXT }\end{array}$ \\
\hline $\begin{array}{l}35 \mathrm{RHT} \\
12 \mathrm{RXT}\end{array}$ & $\begin{array}{l}35 \mathrm{RHT} \\
12 \mathrm{RXT}\end{array}$ & 3 RHT \\
\hline $\begin{array}{l}30 \text { RHT } \\
10 \text { RXT }\end{array}$ & $\begin{array}{l}30 \text { RHT } \\
10 \text { RXT }\end{array}$ & 4 RHT \\
\hline 25 RHT & $\begin{array}{r}\text { Right head tilt } \\
35 \mathrm{RHT} \\
8 \mathrm{RXT}\end{array}$ & $\begin{array}{l}\text { Left head tilt } \\
20 \mathrm{RHT} \\
12 \mathrm{RXT}\end{array}$ \\
\hline
\end{tabular}

RHT = right hypertropia; RXT = right exotropia.

treatment of Brown's syndrome and superior oblique overaction. It overcomes some of the previously mentioned problems associated with tenotomy. The amount of tendon lengthening can be quantified allowing more predictability in the degree of superior oblique weakening and the frequency of postoperative superior oblique paresis is reduced when compared with tenotomy. ${ }^{10}$ Interference with the superior oblique insertion is unnecessary. The technique also allows the possibility of increasing or reversing the procedure at a later date if necessary.

Skew deviation describes an acquired, vertical deviation of the eyes resulting from supranuclear dysfunction. Causative lesions include tumours, vascular lesions, and demyelination. The site of these lesions was originally thought to be in the posterior fossa or cerebellum, but other areas have now been implicated including the brain stem. ${ }^{11}$

Skew deviations have many different presentations. These range from the classic 'one eye down and the other eye up' in a moribund patient to a sudden onset, minor incomitant vertical devia-

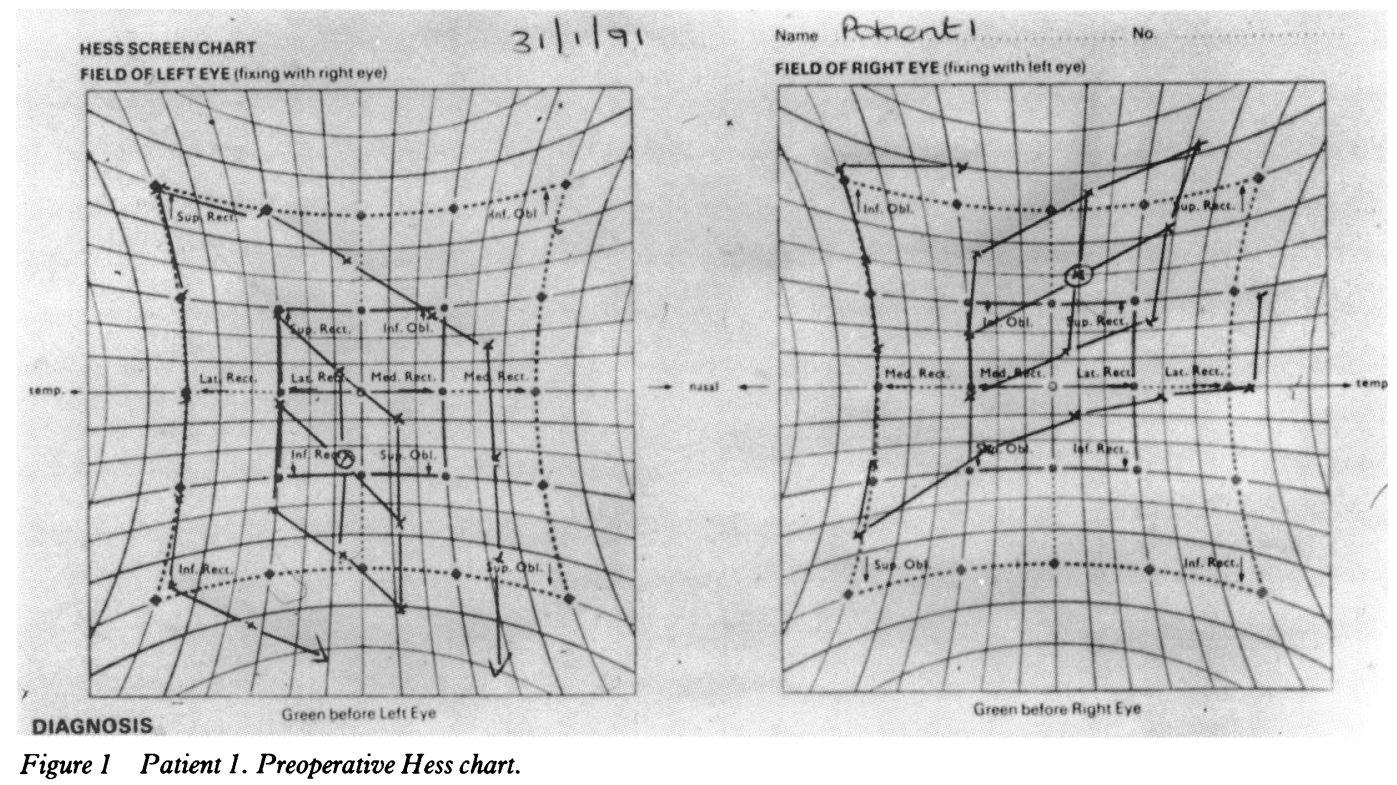




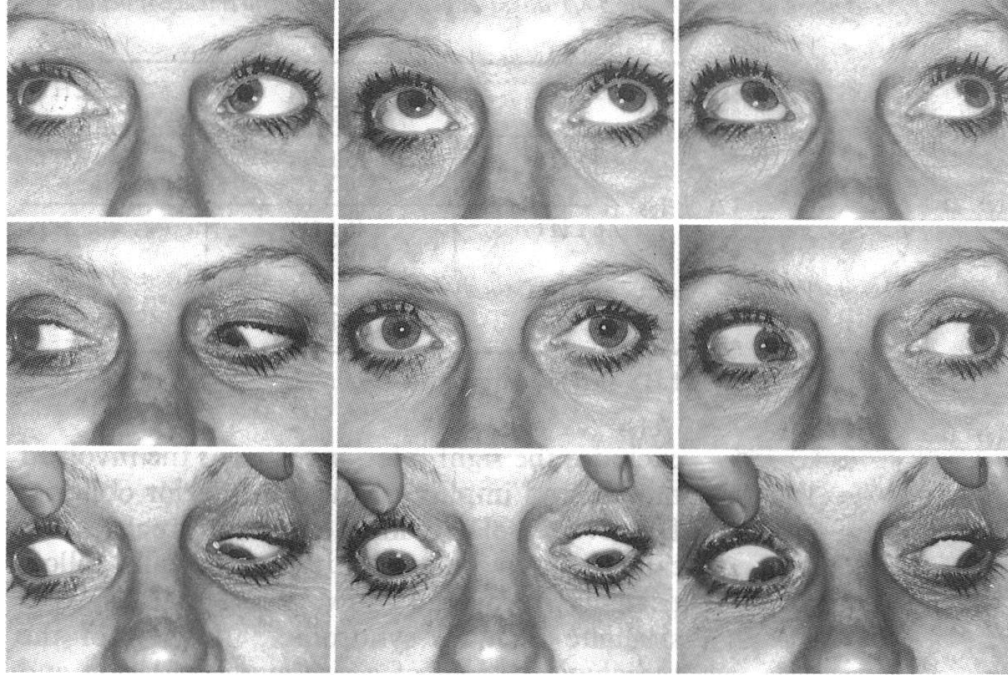

Figure 2 Patient 1. Skew deviation in nine positions of gaze.

tion in an otherwise fit patient. The wide variety of clinical pictures probably reflects the various sites and types of causative lesions.

We present two patients with unilateral superior oblique overaction, in one patient due to skew deviation. In the other the diagnosis is less clear, but we feel that a skew deviation is the most likely cause. Each demonstrated large vertical deviations in the primary position with marked incomitance and unilateral superior oblique overaction. They were treated by superior oblique tendon lengthening together with contralateral superior rectus recession, with excellent results.

\section{Patients and methods}

PATIENT 1

A 45-year-old woman had a cerebrovascular accident (CVA) in 1987 leaving her ataxic and dysphasic. Five years later she had a second CVA affecting the brain stem resulting in vertical diplopia and loss of balance. She presented with a compensatory head posture (CHP) of face turn to the right. The measurements of her deviation in nine positions of gaze and with head tilts are
Table 2 Patient 1: postoperative measurements of ocular deviation

\begin{tabular}{l|c|c}
\hline $\begin{array}{c}12 \mathrm{LHT} \\
7 \mathrm{XT}\end{array}$ & $6 \mathrm{X}$ & 0 \\
\hline $\begin{array}{c}8 \mathrm{LHT} \\
3 \mathrm{XT}\end{array}$ & $2 \mathrm{X}$ & 0 \\
\hline $\begin{array}{l}6 \mathrm{LHT} \\
3 \mathrm{XT}\end{array}$ & 0 & 0 \\
Near $3 \mathrm{X}$ & $\begin{array}{c}\text { Right head tilt } \\
0\end{array}$ & $\begin{array}{c}\text { Left head tilt } \\
0\end{array}$
\end{tabular}

LHT=left hypertropia; XT=exotropia; $X=$ exophoria; $0=$ orthophoria.

shown in Table 1 with Hess chart (Fig 1) and preoperative photographs (Fig 2). The field of binocular single vision was assessed quantitatively as described by Woodruff $e t a l^{12}$ and was found to score $4 / 124$ - that is, $3 \cdot 2 \%$. The deviation remained stable for 6 months.

A left superior oblique tendon lengthening procedure was performed, with $7 \mathrm{~mm}$ of silicone 240 retinal band inserted into the nasal portion of the tendon as described by Wright, ${ }^{9}$ together with a right superior rectus recession of $4 \mathrm{~mm}$.

Postoperatively the patient had no CHP and no diplopia in the primary position (Table 2). The postoperative Hess chart (Fig 3) and ocular movements (Fig 4) were much improved. Her field of binocular single vision was enlarged to $98 \cdot 4 \% \quad($ score $=122 / 124)$. This result has remained stable for 12 months.

\section{PATIENT 2}

A 40-year-old woman fell with loss of consciousness, hitting her left forehead and sustaining superficial skin lacerations and lid bruising. On recovery she had vertical diplopia. This could be controlled with a CHP of right head tilt and left face turn. Measurements of her ocular deviation are shown in Table 3 with Hess chart (Fig 5) and photographs (Fig 6). The field of binocular single vision was $3 \cdot 2 \%($ score $=4 / 124)$. Orbital $x$ rays and computed tomograms were normal. In addition a magnetic resonance image scan, performed to exclude an underlying structural intracranial lesion, was normal. Differential diagnosis included a post-traumatic inferior rectus palsy

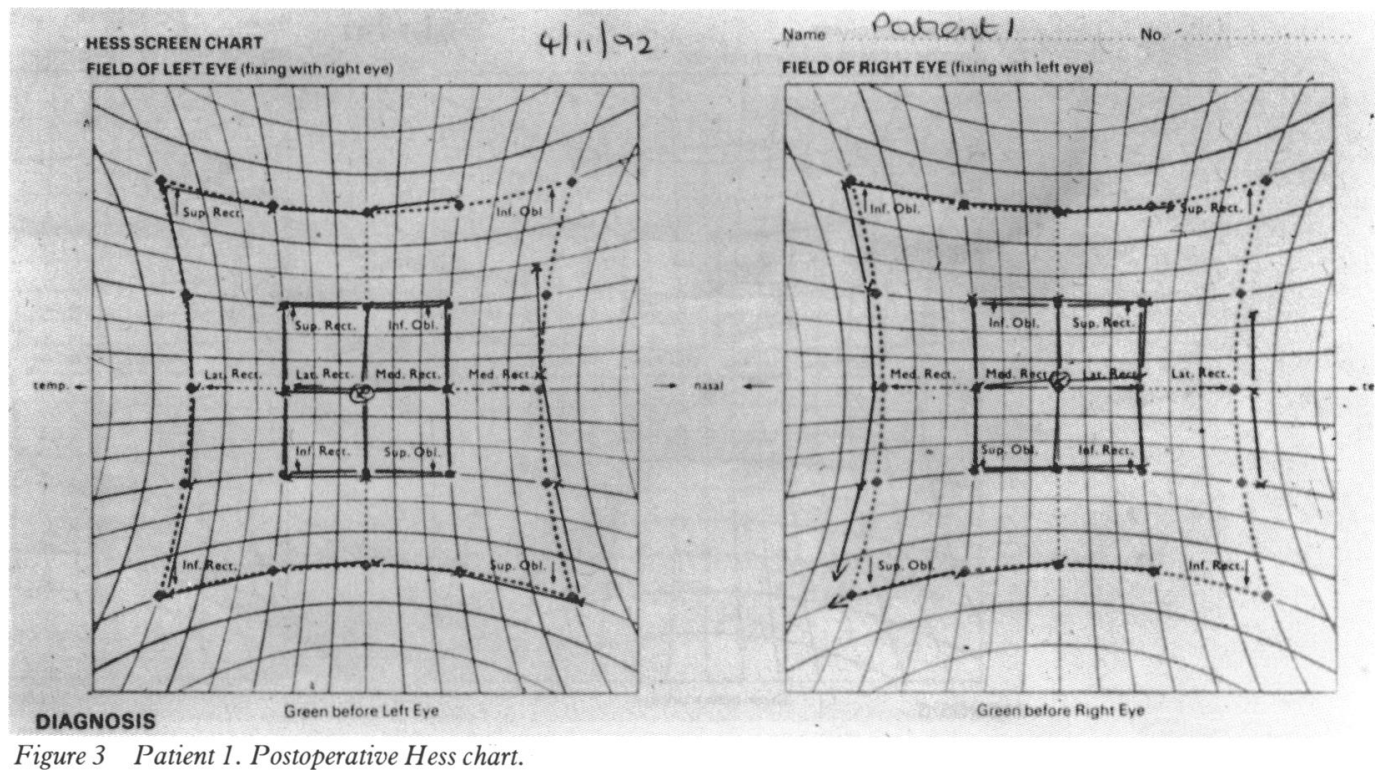



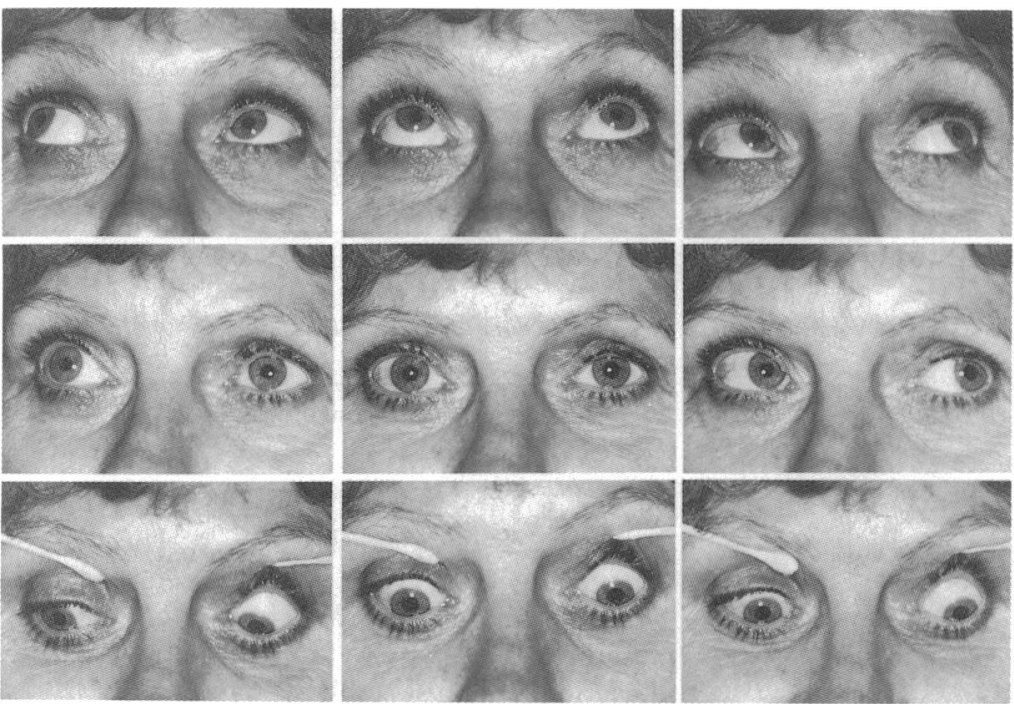

Figure 4 Patient 1. Postoperative photographs.

due to haemorrhage within the muscle and a skew deviation following a CVA.

This patient underwent a right superior oblique tendon lengthening procedure using $7 \mathrm{~mm}$ of silicone 240 band, together with a left superior rectus recession of $4 \mathrm{~mm}$.

Postoperatively she was orthotropic in all positions of gaze with minimal CHP. Table 4 shows the measurements of ocular deviation with postoperative Hess chart in Figure 7 and photographs in Figure 8. The field of binocular single vision had improved to $100 \%$ (score $=124 / 124)$. This result has remained stable for 6 months since surgery.

\section{Discussion}

We believe that patient 1 demonstrated a skew deviation. She had suffered a CVA 5 years previously and presented to us having had a recent brain stem CVA, confirmed radiologically, resulting in diplopia and loss of balance. The differential diagnosis of a supranuclear skew deviation in this case is of an isolated muscle palsy. Park's three step test ${ }^{13}$ in this patient
Table 3 Patient 2: preoperative measurements of ocular deviation

\begin{tabular}{|c|c|c|c|}
\hline & 3 LHT & $\begin{array}{c}12 \mathrm{LHT} \\
6 \mathrm{XT}\end{array}$ & $20 \mathrm{LHT}$ \\
\hline & 4 LHT & $\begin{array}{c}25 \mathrm{LHT} \\
6 \mathrm{XT} \\
\end{array}$ & $40 \mathrm{LHT}$ \\
\hline & $6 \mathrm{LHT}$ & $\begin{array}{l}40 \mathrm{LHT} \\
10 \mathrm{XT}\end{array}$ & 40 LHT \\
\hline Near & $\begin{array}{l}16 \mathrm{LHT} \\
10 \mathrm{XT}\end{array}$ & $\begin{array}{l}\text { Right head trilt } \\
18 \mathrm{LHT}\end{array}$ & $\begin{array}{l}\text { Left head tilt } \\
35 \mathrm{LHT}\end{array}$ \\
\hline
\end{tabular}

LHT=left hypertropia; XT = exotropia.

excludes the right inferior rectus as the involved muscle and implicates the left inferior oblique. However, isolated inferior oblique palsies are rare and may be congenital or typically follow partially recovered third nerve palsies, and simulate Brown's syndrome. ${ }^{14}$ In view of the radiological proof of a supranuclear lesion and the clinical features, we diagnosed her incomitant vertical deviation as a skew deviation.

The diagnosis of patient 2 was less clear. Her history of a fall with loss of consciousness is not typical of a patient presenting with a skew deviation. On prism cover test she had a 25 prism dioptre vertical deviation in the primary position, increasing on left gaze and reducing to virtual orthophoria on right gaze. The position of maximum deviation was on gaze down and to the left in the field of action of the right superior oblique and associated with marked overaction of this muscle on versions. The patient sustained trauma to the left side of the head during her fall. The differential diagnosis thus included a blow out fracture of the left orbit but this was excluded by orbital $x$ rays and computed tomogram. In addition, full ductions in all gaze positions eliminated a mechanical cause for the deviation. Another possibility is that the injury may have induced an inferior rectus haematoma causing relative paresis of this muscle and subsequent overaction of the right superior oblique, the contralateral agonist. However, Park's three step test for isolating cyclovertical muscle palsies, points to a right inferior oblique underaction in this case. The Park's three step test can be

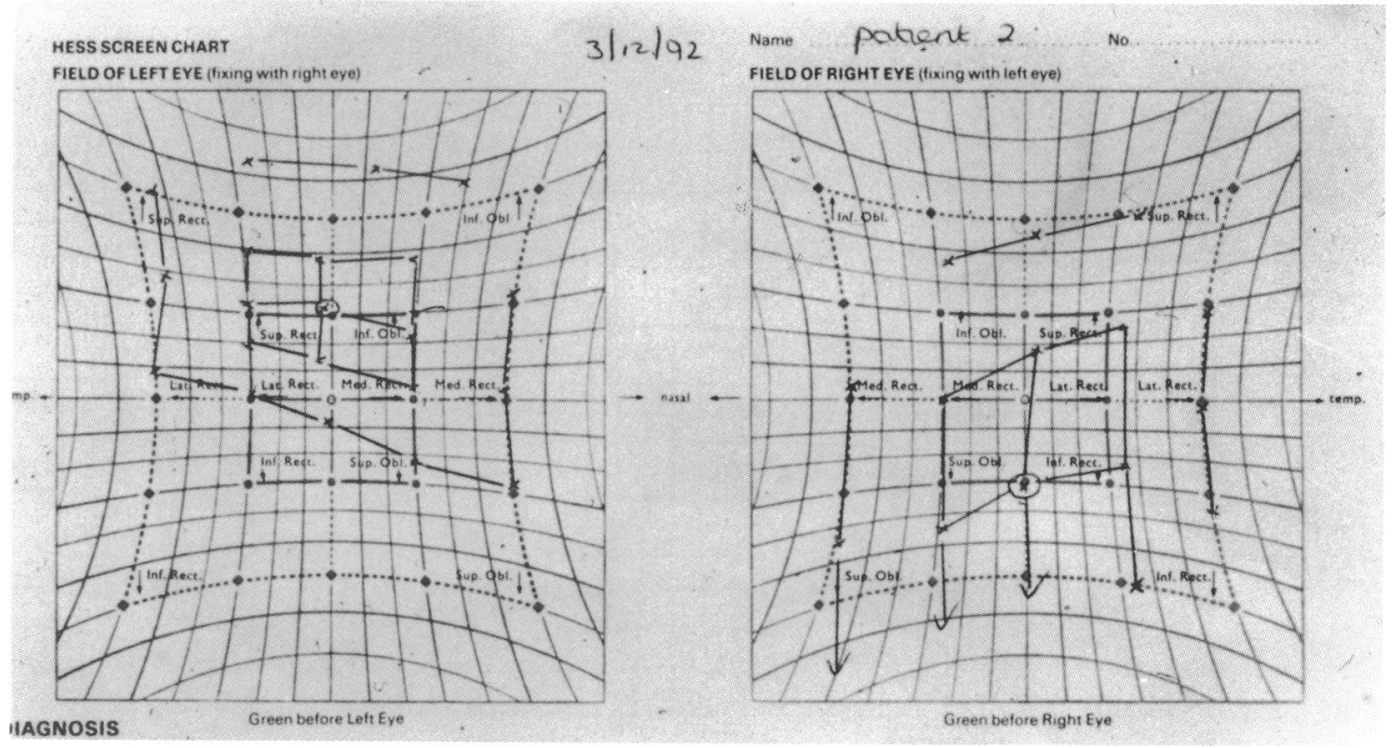

Figure 5 Patient 2. Preoperative Hess chart. 


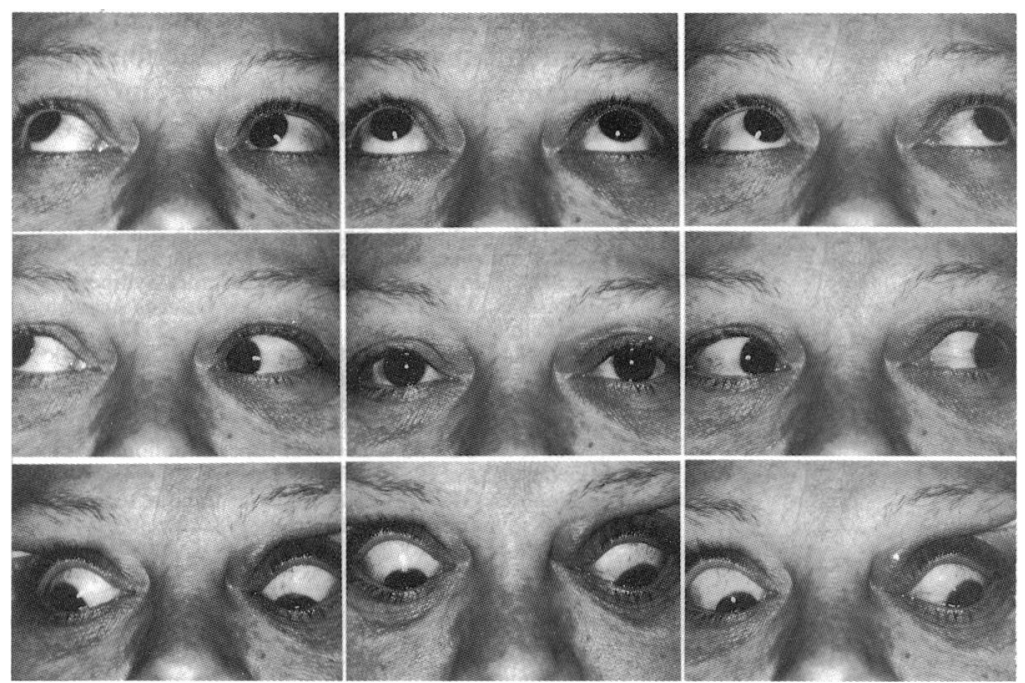

Figure 6 Patient 2. Skew deviation in nine positions of gaze.

misleading ${ }^{15}$ and does not exclude, although does point against, an inferior rectus palsy. We feel, however, that it is most likely that this patient also had a skew deviation although the diagnosis is less clear cut than in patient 1 .

Classic skew deviation presents as a concomitant vertical deviation but incomitant skew deviations are well described. Hamed et $a l^{16}$ report seven patients with alternating skew on lateral gaze that simulated bilateral superior oblique overactions. Lawton-Smith et $a l^{17}$ described skew deviations that were incomitant and mimicked inferior rectus paresis, superior rectus paresis, inferior oblique paresis, or superior oblique overaction. They also describe the presence of skew deviation in patients showing a marked difference in the size of their vertical deviation from left to right gaze. Our two patients showed similarities to these groups. The possibility of a skew deviation should be considered in patients with a neurological history demonstrating a vertical deviation not consistent with a single muscle paresis.

The presenting symptom for both our patients was diplopia, relieved by adopting a marked
Table 4 Patient 2: postoperative measurements of ocular deviation

\begin{tabular}{c|c|c}
\hline 0 & $1 \mathrm{X}$ & $\mathrm{o}$ \\
\hline $\mathrm{o}$ & $\mathrm{o}$ & $1 \mathrm{LH}$ \\
\hline $\mathrm{o}$ & $\mathrm{o}$ & $3 \mathrm{H}$ \\
Near $\mathrm{o}$ & $\begin{array}{c}\text { Right head tilt } \\
\mathrm{o}\end{array}$ & $\begin{array}{c}\text { Left head tilt } \\
1 \mathrm{X}\end{array}$ \\
\hline
\end{tabular}

LH=left hypertropia; $\mathrm{X}=$ exophoria; $\mathrm{o}=$ orthophoria.

compensatory head posture which neither patient could maintain comfortably. Prismatic correction was not a practical therapeutic option owing to the degree of incomitance and the size of the deviation. Surgical correction was therefore the only other possibility, the aim being to reduce the deviation in the primary position to within controllable limits, thus eliminating the compensatory head posture and to increase the field of binocular single vision. The rationale for the choice of surgery in these patients was as follows: the incomitant nature of the deviation and associated superior oblique overaction indicated that a weakening procedure of that muscle was required. We chose a tendon lengthening procedure because of the known unpredictability and complications associated with other weakening procedures of the superior oblique $^{5-8}$ and the results previously reported using this technique were favourable. ${ }^{910}$ The contralateral superior rectus was also weakened because of the large deviation in primary position and associated persistent deviation on upgaze, out of the field of action of the superior oblique. The superior rectus weakening procedure selected for each case was a recession. Since surgery was performed on both the superior oblique and contralateral superior rectus muscle, the specific effect of the operation on the superior oblique cannot be derived from our data.

Patient 1 has been followed for 12 months postoperatively and patient 2 for 6 months. Both have shown a marked and stable improvement from their preoperative situation. Each patient has essentially normal eye movements with elimination of superior oblique overaction.

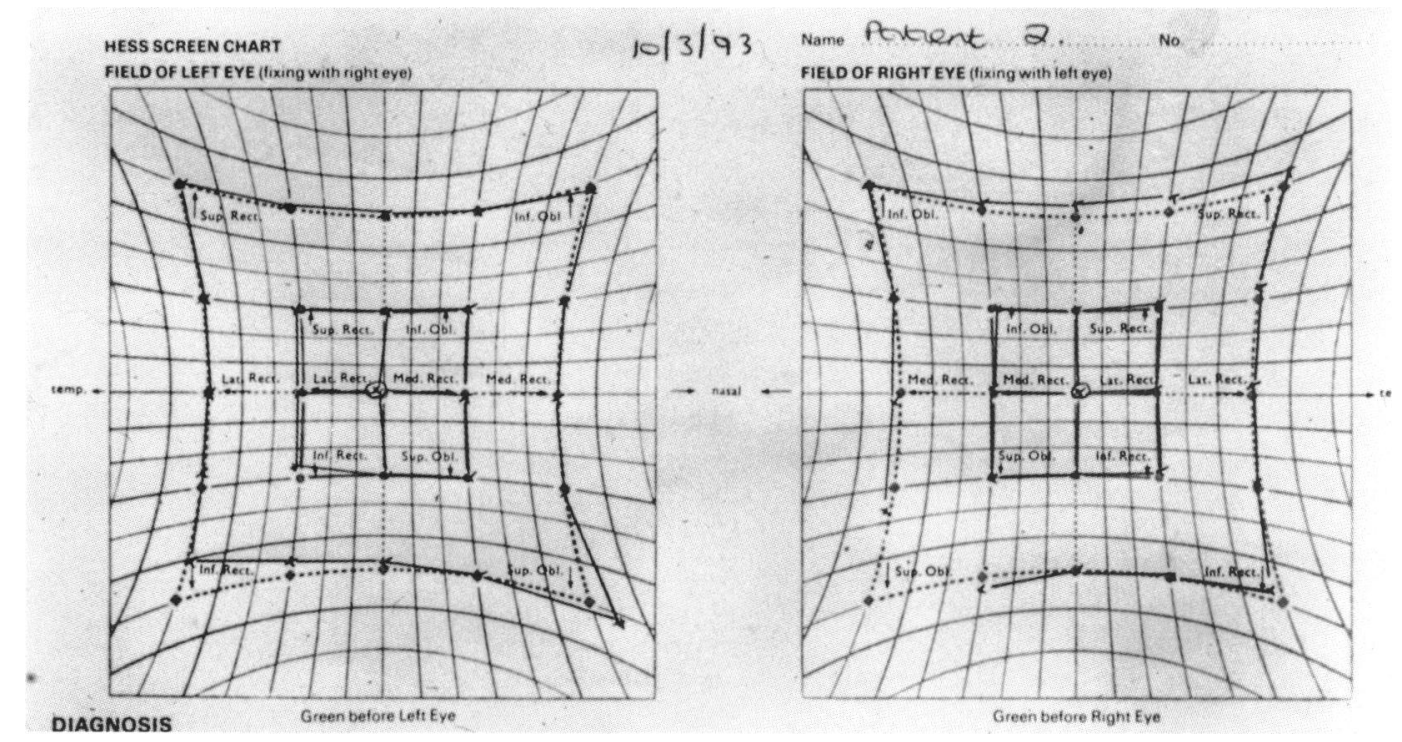

Figure 7 Patient 2. Postoperative Hess chart. 


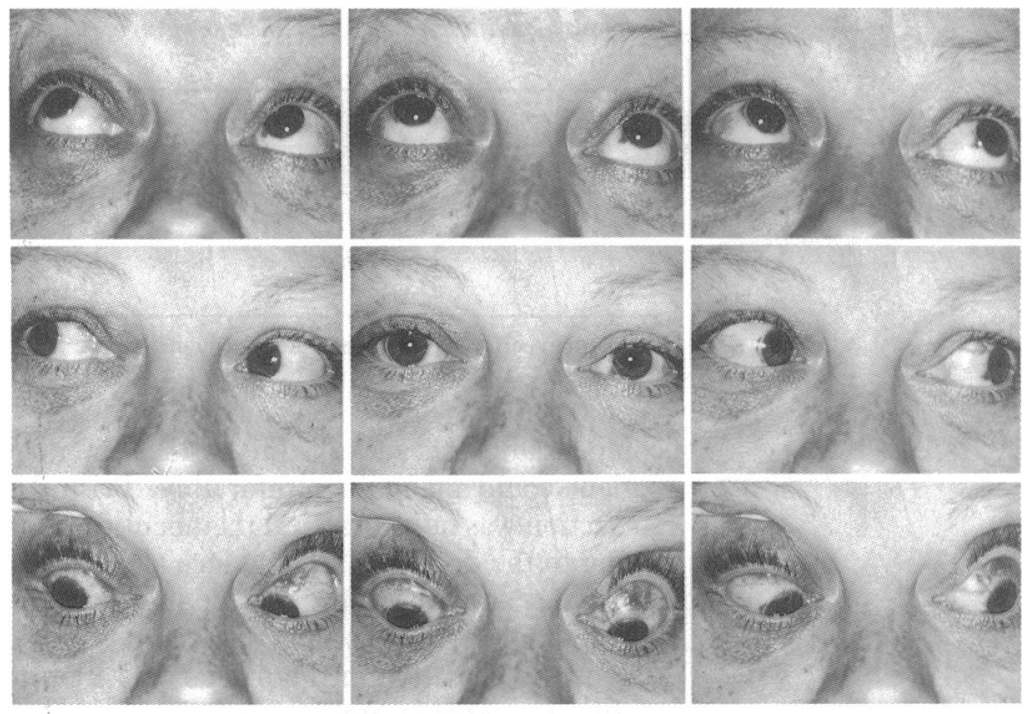

Figure 8 Patient 2. Postoperative photographs.

Patient 1 still has a right hypertropia on right gaze but is able to maintain single vision in the primary position and does not need to adopt a compensatory head posture. There is also a significant increase in the field of single vision to the right. Patient 2 has orthotropia in all gaze positions with minimal compensatory head posture.

Superior oblique tendon lengthening has proved easy to perform and has shown no complications. While further documentation of this procedure in such patients is needed, superior oblique tendon lengthening should be considered as an option for the treatment of cases of acquired superior oblique overaction including certain cases of skew with large, incomitant deviation associated with superior oblique overaction.

1 Brown HW. True and simulated superior oblique tendon sheath syndrome. Doc Ophthalmol 1973; 34: 123-36.

2 Parks MM. Surgery for Brown's syndrome. Symposium on Strabismus. Transactions of the New Orleans Academy of Ophthalmology. St Louis: Mosby, 1978: 157-77.

3 Berke RN. Tenotomy of the superior oblique muscle for hypertropia. Arch Ophthalmol 1947; 38: 605-44.

4 Caldeira JA. Graduated recession of the superior oblique muscle. Br f Ophthalmol 1975; 59: 553-9.

5 McNeer KW. Untoward effects of superior oblique tenotomy. Ann Ophthalmol 1972; 4: 747-55.

6 Von Noorden GK, Olivier P. Superior oblique tenectomy in Brown's syndrome. Ophthalmology 1982; 89: 303-8.

7 Scott WE, Jampolsky AJ, Redmond MR. Superior oblique tenotomy: indications and complications. Int Ophthalmol Clin 1976; 16: 151-9.

8 Crawford JS, Orton RB, Labow-Daily L. Late results of superior oblique muscle tenotomy in true Brown's syndrome. Am 7 Ophthalmol 1980; 89: 824-9.

9 Wright KW. Superior oblique silicone expander for Brown syndrome and superior oblique overaction. $\mathcal{F}$ Pediatr Ophthalmol Strabismus 1991; 28: 101-7.

10 Wright KW, Min B, Park C. Comparison of superior oblique tendon expander to superior oblique tenotomy for the management of superior oblique overaction and Brown management of superior oblique overaction and Brown
syndrome. $\mathcal{F}$ Pediatr Ophthalmol Strabismus 1992; 29: 92-7.

11 Keane JR. Ocular skew deviation. Analysis of 100 cases. Arch Neurol 1975; 32: 185-90.

12 Woodruff G, O'Reilly C, Kraft SP. Functional scoring of the field of binocular single vision in patients with diplopia. Ophthalmology 1987; 94: 1554-61.

13 Parks MM. Isolated cyclovertical muscle palsy. Arch Ophthalmol 1958; 60: 1027-35.

14 Scott WE, Nankin SI. Isolated inferior oblique paresis. Arch Ophthalmol 1977; 95: 1586-93.

15 Von Noorden GK, Hansell R. Clinical characteristics and treatment of isolated inferior rectus paralysis. Ophthalmology 1991; 98: 253-7.

16 Hamed LM, Maria BL, Quisling RG, Mickle JP. Alternating skew on lateral gaze. Ophthalmology 1993; 100: 281-6.

17 Smith JL, David NJ, Klintworth G. Skew deviation. Neurology 1964; 14: 96-105. 